\title{
Questionable Dementia: Clinical Course and Predictors of Outcome
}

\author{
D.P. Devanand, MD, "¥\$ Mara Folz, BA," Marianne Gorlyn, BA," James R. Moeller, $P h D,{ }^{+\$}$ and \\ Yaakov Stern, $P h D^{\neq m \| *}$
}

OBJECTIVE: To evaluate the clinical course and predictors of outcome in outpatients with cognitive impairment who do not meet criteria for dementia at initial evaluation.

DESIGN: Naturalistic longitudinal study.

METHODS: Cognitively impaired patients in a memory disorders clinic who fell between the "normal" and "dementia" categories were defined broadly as "questionable dementia" (QD). Of 127 consecutive QD patients, 75 were followed for a minimum of 1 year (mean 2.5 years, SD 1.7). Baseline neuropsychological testing was conducted in 62 of these 75 QD patients.

RESULTS: : At the final follow-up time-point, $41.3 \%$ met diagnostic criteria for dementia (27 of 31 patients with dementia had possible or probable Alzheimer's Disease, AD), $44 \%$ were rated as not demented, and $14.7 \%$ remained as "uncertain" dementia. Increased age was associated with the final diagnosis of dementia, but duration of follow-up, Clinical Dementia Rating, and modified Mini Mental State (mMMS) scores were not predictive. Low scores on the mMMS delayed recall subtest, consistent long-term retrieval on the Selective Reminding Test, category naming for animals, and the WAIS-R digit symbol, picture arrangement, and block design subtests were predictive of the final diagnosis of dementia (all $P \leq .01$ ). mMMS delayed recall showed $66.7 \%$ sensitivity and $71.4 \%$ specificity, the other five neuropsychological subtests together showed $66.7 \%$ sensitivity and $66.7 \%$ specificity, and the six tests together showed $81 \%$ sensitivity and $76.9 \%$ specificity. Similar predictive accuracy was obtained for the final diagnosis of AD.

CONCLUSIONS: In QD patients, poor performance on the mMMS delayed recall item may be a useful predictor of the diagnosis of dementia (and AD) on follow-up. Combining a screening instrument like the mMMS with specific neuropsy-

From the "Memory Disorders Center and the ${ }^{\dagger}$ Department of Biological Psychiatry in the New York State Psychiatric Institute, the ${ }^{\ddagger}$ Center for Alzheimer's Disease Research in New York City, the "Gertrude H. Sergievsky Center, and the Departments of SPsychiatry, "Neurology and the Division of "Epidemiology in the School of Public Health in the College of Physicians and Surgeons of Columbia University, New York, New York.

This work was supported in part by Federal Grants MH44176, MH50038, RR00645, AG08702, AG10963, and the Charles S. Robertson Memorial Gift for research in Alzheimer's Disease.

Presented at the annual meeting of the American College of Neuropsychopharmacology, San Juan, Puerto Rico, 1995.

Address correspondence to D.P. Devanand, MD, New York State Psychiatric Institute, 722 West 168th St., Unit 72, New York, NY 10032. chological tests may provide good predictive accuracy. In QD patients, the observed heterogeneity in diagnostic outcome, with most patients in the "dementia" and "no dementia" categories at follow-up, enhances the feasibility of evaluating early markers with predictive accuracy for dementia and AD. J Am Geriatr Soc 45:321-328, 1997.

G rowing numbers of cognitively impaired, nondemented Isubjects are presenting for clinical evaluation. ${ }^{1,2}$ Prevalence estimates range from 1 to $10 \%$, primarily because of the difficulty in defining the boundaries between "normal," "cognitive impairment," and "dementia" in older people. ${ }^{3-6}$ The terms "benign senescent forgetfulness" and "age-associated memory impairment" have been used to describe variants of normal aging. ${ }^{7-9}$ Earlier evidence of uniformly good progno$\mathrm{sis}^{8,9}$ has been questioned in recent studies. ${ }^{10-12}$ In a series of outpatients with "questionable dementia" (Clinical Dementia Rating, $\mathrm{CDR}=.5$ ), nearly all deteriorated on followup. ${ }^{12-14}$ The authors acknowledged that in their hands, "questionable dementia" represented a very early stage of AD. These discrepant outcomes can be explained partly by the samples studied, which have ranged from older subjects responding to advertisements to outpatients in clinics. ${ }^{11,12}$ Nonetheless, it remains unclear as to whether these cognitively impaired individuals are merely aging "normally" or have very early dementia.

In $A D$, postulated risk factors include the presence of the apolipoprotein- $\epsilon 4$ allele, ${ }^{15,16}$ family history of dementia, ${ }^{17}$ head injury, ${ }^{18}$ depression, ${ }^{19}$ advanced age of the mother, ${ }^{20}$ exposure to chemical toxins, cigarette smoking, ${ }^{21}$ and low premorbid intelligence and education. ${ }^{22}$ In addition, a variety of neuropsychological tests have been proposed as early diagnostic markers. Community studies indicate that subtle deficits in memory and language precede the onset of dementia by several years. ${ }^{23-27}$ In clinical samples, delayed word recall ${ }^{28}$ and delayed story-telling ${ }^{29}$ have demonstrated good predictive accuracy in distinguishing mild dementia from normal controls. However, attempts to generate a discriminant function from neuropsychological test scores to distinguish patients with mild $A D$ from normal controls have been only partly successful. ${ }^{12,14,30,31}$

We use the term "Questionable Dementia" (QD) to describe a broad group of patients who present with cognitive impairment and fall between the "normal" and "dementia" categories. This exploratory, naturalistic, longitudinal study had two goals: to examine the clinical features of QD patients, and to assess the utility of specific clinical features and 
neuropsychological test measures in predicting who met criteria for dementia, or $\mathrm{AD}$, at follow-up.

\section{METHODS}

\section{Initial Evaluation}

The study sample was selected from outpatients who presented consecutively to a Memory Disorders Clinic that focuses on research in Alzheimer's disease and related disorders. A physician (neurologist or psychiatrist) obtained a semistructured, detailed medical history and conducted a physical and neurological examination. The physician also completed several rating scales: brief screen for psychosis and major depression based on the DSM-III-R criteria, ${ }^{32}$ abbreviated version of the Columbia University Parkinson's Disease Evaluation, ${ }^{33}$ modified Hachinski Ischemic Scale, ${ }^{34}$ Clinical Dementia Rating (CDR), ${ }^{13}$ modified Blessed Functional Activity Scale (BFAS parts 1 and 2), ${ }^{35,36}$ and the Schwab and England Functional Activity Scale (degree of independence 0 to $100 \%$ ). The mMMS, a modified and expanded version (scoring range 0-57) of the Mini Mental State Examination (MMSE) ${ }^{37}$ was administered. ${ }^{38,39}$ Laboratory workup included complete blood count with differential, serum electrolytes, liver and renal function tests, thyroid function tests, VDRL, serum $B_{12}$ and folate levels, and either CT or MRI scan of brain. Additional tests, eg, EEG, CSF studies, were conducted when indicated. In all cases, the examining physician reviewed the evaluation with a senior neurologist and then completed a formal summary with diagnostic impression. Most patients also received a battery of neuropsychological tests administered by technicians who were trained and closely supervised by a senior neuropsychologist (Y.S.) throughout the study period.

The neuropsychological battery included tests for orientation, memory (verbal and nonverbal), abstract reasoning, language, and visuospatial abilities. The following tests were administered: Wechsler Adult Intelligence Scale Revised version (WAIS-R, scaled scores were used), Rosen Drawing Test, Controlled Oral Word Association, Selective Reminding Test (SRT, 12 item, 6 trial version; 15 minute delay), selected subtests from the Boston Diagnostic Aphasia Evaluation (BDAE, category naming and right-left orientation), Boston Naming Test, Benton Visual Retention Test, and Target Finding (cancellations and TMX). The technician reviewed the neuropsychological evaluation with a senior neuropsychologist (Y.S.), and a diagnostic impression and report were completed.

All the available information, including the physician's evaluation and the neuropsychologist's report, was evaluated in a weekly conference of physicians and neuropsychologists, and a consensus diagnosis was reached. The diagnosis of dementia was based on DSM-III-R criteria, and the diagnosis of possible or probable AD was based on NINCDS-ADRDA criteria. ${ }^{40}$ For both demented and nondemented patients, all possible causes of cognitive impairment were specified.

A psychiatrist experienced in the evaluation of patients with dementia reviewed all charts to determine if study inclusion/exclusion criteria were met (see Appendix). To make this determination, the psychiatrist rater utilized all available clinical and laboratory information, but remained blind to follow-up data. Patients who were considered normal for their age, or demented, were excluded. The inclusion/ exclusion criteria for QD were fairly broad, with the goal of providing generalizability to a wide range of clinical settings.

\section{Follow-up}

Patients who returned for follow-up were seen annually. The physician conducted a brief neuropsychiatric evaluation (including mMMS administration) and completed the CDR. If the physician's diagnostic impression or CDR rating changed, neuropsychological testing was repeated and a diagnostic consensus conference was held. All available information, including the report from the diagnostic consensus conference, was used by the psychiatrist to classify each patient's follow-up diagnosis in three ways: (1) no dementia, $\mathrm{QD}$, dementia; (2) no $\mathrm{AD}$, possible $\mathrm{AD}$, probable $\mathrm{AD}$; (3) specific etiology for cognitive impairment, or dementia. For all patients, the diagnosis at the end-point, i.e., last follow-up visit, was the main outcome measure examined.

\section{Statistical Analyses}

All analyses were conducted using the SAS package. Chi-squared statistics or two-tailed $t$ tests were used to compare the demographic and clinical features in patients who met criteria for dementia on follow-up with the rest of the sample. Univariate analyses were conducted with the baseline neuropsychological test scores as predictors of final diagnosis. To reduce Type I error, only those test scores $\leq .01$ level of significance (two-tailed) in univariate analyses were evaluated as predictors in discriminant function analyses. Sensitivity and specificity of the discriminant function for the final diagnosis, and sensitivity and specificity of the individual test scores in the discriminant function, were calculated. Splithalf reliability of the discriminant function was evaluated. For all discriminant function analyses, the sample outcome data were used to establish the expected base rates.

\section{RESULTS}

Of 828 new patients evaluated in the clinic over a 7 -year period, 127 met study inclusion/exclusion criteria (Appendix). Medication use (high dose benzodiazepines and anticholinergic effects of psychotropics) that was deemed the likely etiology for cognitive impairment led to sample exclu$\operatorname{sion}(\mathrm{n}=5)$. Medications that could affect cognition but were not rated as the likely etiology, primarily because of the low dosages used, were not grounds for exclusion. These included tricyclic antidepressants (4 patients, each on $\leq 50 \mathrm{mg} /$ day imipramine equivalents), selective serotonin reuptake inhibitors ( $\mathrm{n}=5$ ), low-dose benzodiazepines ( $\leq 3 \mathrm{mg} /$ day lorazepam equivalents, $n=9$ ), beta blockers $(n=4)$, and ranitidine or cimetidine $(n=4)$. The use of these medications was not associated with a final diagnosis of dementia $\left(\chi^{2}=.06\right.$; $P=.809)$.

\section{Initial Evaluation}

The majority $(59.1 \%)$ of patients were women, $55.5 \%$ were retired, and $93.4 \%$ were right-handed. The ethnic composition was $82.1 \%$ white, $8.9 \%$ Hispanic, $6.3 \%$ black, and $2.7 \%$ in other categories. The mean age was 66.2 years (SD 10.0 ), and the mean educational attainment was 14.2 years (SD 3.1). The mean duration of illness was 3.5 years (SD 4.1), mean mMMS was 48.5 (SD 4.9), and mean BFAS was 1.5 (SD 1.3). Patients were rated $91.6 \%$ (SD 10) independent.

At initial evaluation, $61.3 \%$ had a CDR of 0 and $38.7 \%$ had a CDR of 0.5. No specific etiology for cognitive impair- 
ment could be identified in $40.4 \%$ of the QD sample. For patients with more than one possible etiology $(14.6 \%)$, the cause judged to be most contributory was used in analysis. Depression $(28.6 \%)$ and cerebrovascular disease $(19 \%)$ were the most commonly identified etiologies, and alcohol abuse $(4.8 \%)$ was less commonly rated as the likely cause. Past psychiatric history (broadly defined) and family histories of dementia, psychiatric disorder, and stroke were common (Table 1). Extrapyramidal signs, predominantly minimal to mild in severity, occurred in $18 \%$. Psychosis $(3.1 \%)$ was rare and myoclonus $(0 \%)$ was absent.

\section{Follow-up}

Of the 127 QD patients, $75(60 \%)$ completed at least 1 year of follow-up (mean 2.5 years, SD 1.7). The loss to follow-up was partly because this was an exploratory, naturalistic study. Also, the first 25 to $30 \mathrm{QD}$ patients seen in the clinic were asked to return a year later only if they felt the need.

The final available evaluation was taken as the follow-up time point. There was a high rate of diagnostic clarification during follow-up, resulting in a firm diagnosis of "dementia" or "no dementia" in $85.3 \%$ of cases. At follow-up, 31 $(41.3 \%)$ patients were demented, $33(44 \%)$ patients were not demented, and $11(14.7 \%)$ were rated as "uncertain" dementia (Table 2). Duration of follow-up did not differ between patients who eventually met criteria for dementia ( 2.7 years, SD 1.8) and the rest of the sample (2.3 years, SD $1.7 ; t=1.0$, $P=.316)$. Initial CDR rating $(0$ or 0.5$)$ was not significantly associated with final diagnostic outcome $\left(\chi^{2}=2.1 ; P=.147\right)$.

Table 1. Clinical Features at Initial Evaluation in the QD sample $(\mathrm{n}=127)$

\begin{tabular}{lc}
\hline \multicolumn{1}{c}{ Clinical Features } & $\%$ Sample \\
\hline Referral source & \\
$\quad$ Self & 19.3 \\
Physician & 64.9 \\
Other & 15.8 \\
Presenting complaints & \\
$\quad$ Difficulty with memory & 93.7 \\
Memory as chief complaint & 77.4 \\
Medication status & \\
Currently on medication & 78.6 \\
On medication that may affect cognition & 25.4 \\
Patient history & \\
Hypertension & 36.0 \\
Alcohol abuse & 17.3 \\
Any treatment for psychiatric disorder & 38.1 \\
Family history & \\
$\quad$ Dementia & 36.9 \\
Psychiatric history & 24.8 \\
Cerebrovascular disease & 30.2 \\
Diagnoses: Overall judgement & \\
Cognitive impairment without dementia & \\
$\quad$ (CDR=0) & 61.3 \\
Uncertain dementia (CDR=0.5) & 38.7 \\
Cognitive impairment due to depression & 28.6 \\
Cognitive impairment due to cerebrovascular & \\
$\quad$ disease & 19.0 \\
\hline
\end{tabular}

At follow-up, 27 out of 31 patients rated as demented were diagnosed with possible or probable AD $(87.1 \%)$. Of the remaining four patients, two patients had stroke-related (multi-infarct) dementia and two atypical patients were in a miscellaneous category.

Baseline source of referral, age, gender, marital status, family history of dementia, education, employment status, CDR, mMMS, and neuropsychological test scores did not differ significantly between patients who did $(n=75)$ and did not $(\mathrm{n}=52)$ return for follow-up. Patients who were followed tended to be functionally more impaired at baseline (mean $89.9 \%$ independence, SD 10.4) than those who were not followed (mean 94.3\%; SD 8.9; $t=2.3 ; P=.022$ ). Overall, the absence of significant baseline differences in demographic variables and in indices of severity indirectly suggests that there was little systematic bias as to which patients returned for follow-up.

\section{Clinical Predictors}

The patients who met criteria for dementia on follow-up tended to be older than the rest of the sample (mean 68.6 years; SD 9.8 vs mean 63.0 years; SD $8.5 ; t=2.6, P=.010$ ), but the two groups did not differ significantly on any other demographic variable. Gender, years of education, depression (sum of SCID items), cerebrovascular disease (Hachinski scores), functional ability ( $\%$ independence and BFAS scores), extrapyramidal signs, and family history of dementia were not predictive.

\section{Neuropsychological Testing}

The group that developed dementia on follow-up did not differ significantly from the rest of the sample on baseline mMMS total scores or on the subscale scores of orientation, registration, naming, construction, and language. However, the subscale score for recall ( 3 objects after a 5-minute delay) was significantly lower in patients who became demented (mean 1.0; SD 1.1) compared with the rest of the sample (mean 2.0 SD 1.0; $t=4.0 ; P<.001$ ). Patients who met criteria for dementia on follow-up showed a $27 \%$ decline from baseline in total mMMS scores compared to a $1 \%$ decline in the rest of the sample $(t=4.6 ; P<.001)$.

At baseline, a neuropsychological test battery was administered to 62 of the 75 patients $(82.7 \%)$ who were followed. In univariate analyses $(\alpha \leq .01)$, five baseline neuropsychological test scores distinguished patients who did $(\mathrm{n}=$ 26) and did not $(n=36)$ become demented on follow-up. Patients who became demented had significantly lower baseline scores on three measures from the WAIS-R (digit symbol, picture arrangement, and block design), consistent long-term retrieval (CLTR) on the SRT, and the word fluency test of naming of animals (Table 3). The other test scores did not reach the required level of significance (Table 3). Additional measures from the Controlled Word Association Test, Benton Visual Retention Test, and Target Finding (cancellations and TMX) were not predictive (data not shown).

The five neuropsychological test scores that were each predictive of diagnostic outcome correlated significantly with each other $(r=.40$ to 0.75 ; all $P<.001)$. Consequently, in logistic regression analyses that evaluated prediction of the final diagnosis of dementia, no significant associations were obtained.

Increased age tended to be associated with lower scores on these five neuropsychological test scores and mMMS 
Table 2. Comparison of Initial and Follow-up Diagnoses $(n=75)$

\begin{tabular}{|c|c|c|c|}
\hline Initial Diagnosis & \multicolumn{3}{|c|}{ Diagnosis at Final Evaluation } \\
\hline No dementia CDR $=0$ & 21 & 9 & 16 \\
\hline "Uncertain" dementia CDR $=0.5$ & 12 & 2 & 15 \\
\hline
\end{tabular}

* CDR: Clinical Dementia Rating $(0=$ no dementia, $0.5=$ questionable dementia, $1=$ mild dementia, $2=$ moderate dementia, $3=$ severe dementia).

Table 3. Baseline Neuropsychological Test Scores as Predictors of Final Diagnosis

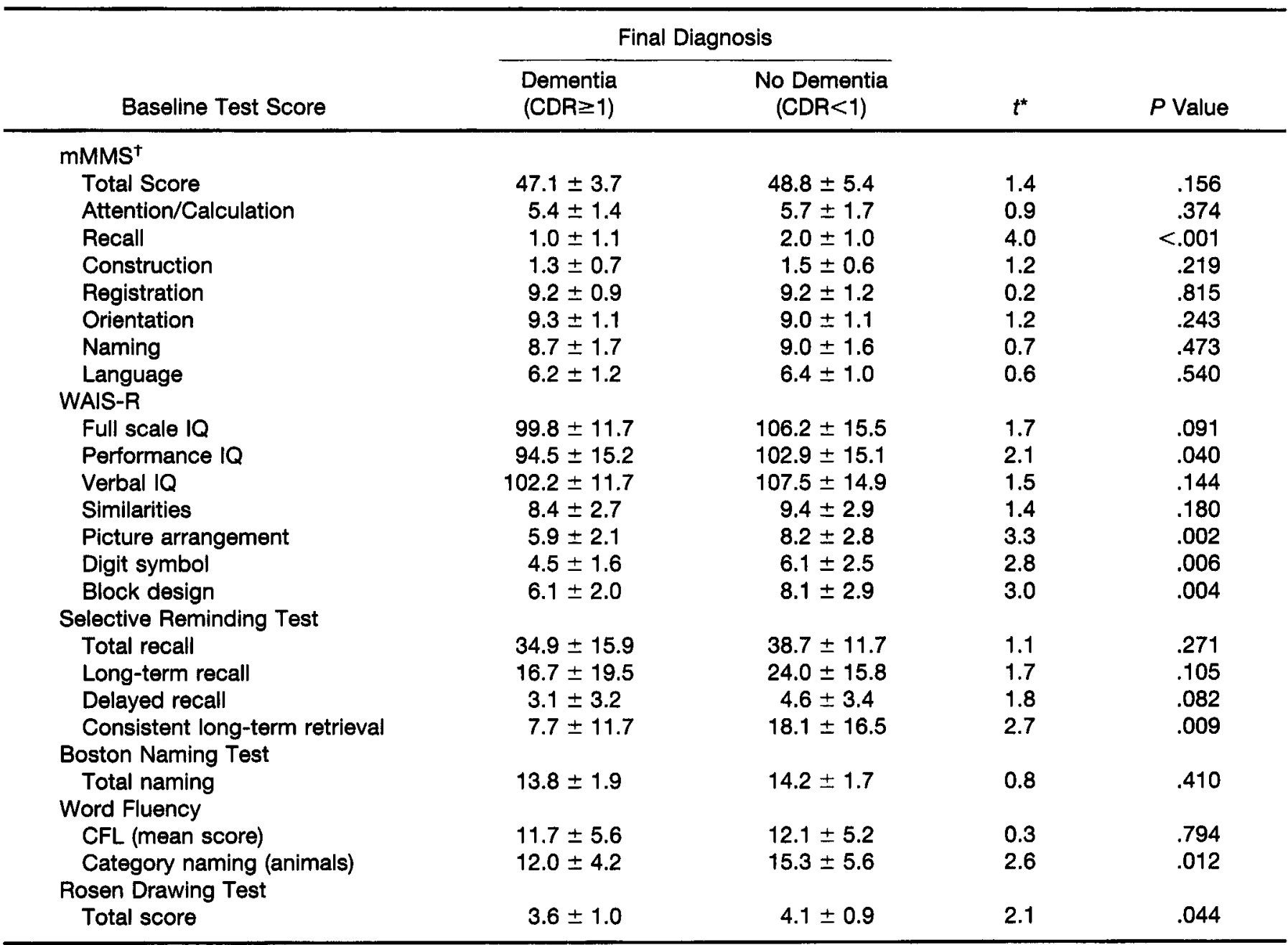

*wo-tailed $t$ test

for mMMS, $n=75$; for other neuropsychological tests, $n=62$.

delayed recall $(r-.29$ to -.58 ; all $P \leq .02)$. Education in years tended to be associated with higher scores on the digit symbol and block design tests from the WAIS-R, CLTR on the SRT, and the word fluency test of naming of animals ( $r .31$ to .46; $P<.02$ ), but showed no significant association with mMMS delayed recall or WAIS-R picture arrangement scores. There was a trend-level association between diagnostic outcome and age $(t=2.6 ; P=.010)$ but not education $(t=1.2 ; P=$ .228 ). Hence age was the only demographic variable evaluated in the discriminant function analyses.

\section{Discriminant Function Analyses}

The results of the discriminant function analyses are displayed in Table 4. For the broad outcome classification of dementia versus the rest of the sample, mMMS delayed recall score showed $66.7 \%$ sensitivity, $71.4 \%$ specificity, $62.5 \%$ positive predictive value, and $75.0 \%$ negative predictive value. The discriminant function using the five neuropsychological test scores showed $66.7 \%$ sensitivity, $66.7 \%$ specificity, $60.9 \%$ positive predictive value, and $72.0 \%$ negative predictive value. There were significant intercorrelations be- 
Table 4. Prediction of Diagnosis of Dementia by Discriminant Function Analysis

\begin{tabular}{|c|c|c|c|c|c|c|c|c|}
\hline \multirow[b]{2}{*}{ Variables } & \multicolumn{4}{|c|}{ Dementia vs Rest of sample } & \multicolumn{4}{|c|}{ Dementia vs No Dementia } \\
\hline & $\begin{array}{c}\% \\
\text { Sensitivity }\end{array}$ & $\begin{array}{c}\% \\
\text { Specificity }\end{array}$ & $\begin{array}{l}\text { Positive } \\
\text { Predictive } \\
\text { Value \% }\end{array}$ & $\begin{array}{c}\text { Negative } \\
\text { Predictive } \\
\text { Value \% }\end{array}$ & $\begin{array}{c}\% \\
\text { Sensitivity }\end{array}$ & $\begin{array}{c}\% \\
\text { Specificity }\end{array}$ & $\begin{array}{l}\text { Positive } \\
\text { Predictive } \\
\text { Value \% }\end{array}$ & $\begin{array}{c}\text { Negative } \\
\text { Predictive } \\
\text { Value \% }\end{array}$ \\
\hline mMMS delayed recall item & 66.7 & 71.4 & 62.5 & 75.0 & 66.7 & 71.0 & 69.0 & 68.8 \\
\hline Score $=0$ & 50.0 & 88.1 & 75.0 & 71.2 & 50.0 & 90.3 & 83.3 & 65.1 \\
\hline Score $\leq 1$ & 66.7 & 71.4 & 62.5 & 75.0 & 66.7 & 71.0 & 69.0 & 68.8 \\
\hline Score $\leq 2$ & 86.7 & 40.5 & 51.0 & 81.0 & 86.7 & 35.5 & 56.5 & 73.3 \\
\hline \multicolumn{9}{|l|}{$\begin{array}{l}5 \text { Neuropsychological test } \\
\text { scores }\end{array}$} \\
\hline $\begin{array}{l}\text { Discriminant Function } \\
\text { Individual Items }\end{array}$ & 66.7 & 66.7 & 60.9 & 72.0 & 85.7 & 59.1 & 66.7 & 81.3 \\
\hline SRT CLTR* & 64.0 & 71.4 & 61.5 & 73.5 & 76.0 & 55.6 & 61.3 & 71.4 \\
\hline WAIS-R ${ }^{\dagger}$ digit symbol & 55.6 & 80.0 & 71.4 & 66.7 & 74.1 & 43.5 & 60.6 & 58.8 \\
\hline WAIS-R picture arrangement & 56.0 & 69.0 & 60.9 & 64.5 & 80.0 & 58.3 & 66.7 & 73.7 \\
\hline WAIS-R block design & 53.6 & 67.7 & 60.0 & 61.8 & 78.6 & 50.0 & 64.7 & 66.7 \\
\hline Category naming of animals & 44.4 & 68.6 & 52.2 & 61.5 & 59.3 & 55.6 & 57.1 & 57.7 \\
\hline \multirow{2}{*}{\multicolumn{9}{|c|}{5 Test Scores and mMMS recall }} \\
\hline & 81.0 & 76.9 & 73.9 & 83.3 & 81.0 & 66.7 & 70.8 & 77.8 \\
\hline
\end{tabular}

* Consistent Long-term retricval on the Selective Reminding Test.

+ Wechsler Adult Intelligence Scale-Revised (scaled scores).

tween these five scores, and the predictive accuracy of each test score is displayed in Table 4. mMMS delayed recall score and the five neuropsychological tests scores taken together showed $81 \%$ sensitivity, $76.9 \%$ specificity, $73.9 \%$ positive predictive value, and $83.3 \%$ negative predictive value. Inclusion of age as a variable in this discriminant function led to $85.7 \%$ sensitivity, $76.9 \%$ specificity, $75.0 \%$ positive predictive value, and $87.0 \%$ negative predictive value. Duration of follow-up did not affect the predictive accuracy of the discriminant function. Results of the discriminant function analyses for the narrower outcome classification of dementia versus no dementia ("uncertain" dementia excluded) are also displayed in Table 4.

Next, discriminant function analyses were conducted for the outcome classification of AD versus no dementia. mMMS delayed recall score showed $52 \%$ sensitivity, $88.1 \%$ specificity, $72.2 \%$ positive predictive value, and $75.5 \%$ negative predictive value. The discriminant function using the five neuropsychological test scores showed $61.1 \%$ sensitivity, $77.8 \%$ specificity, $77.8 \%$ positive predictive value, and $75.0 \%$ negative predictive value. mMMS delayed recall score and the five neuropsychological tests scores taken together showed $77.8 \%$ sensitivity, $84.6 \%$ specificity, $77.8 \%$ positive predictive value, and $84.6 \%$ negative predictive value.

Split-half reliability was evaluated for the discriminant function that utilized all six test scores for the prediction of dementia versus the rest of the sample. Comparable predictive accuracy was obtained, with $72 \%$ and $81.8 \%$ correctly classified in the two halves of the sample, respectively.

\section{DISCUSSION}

In this QD sample, the tests that predicted the diagnosis of dementia encompassed several domains of cognitive function: delayed recall on the mMMS, consistent long-term retrieval on the SRT (long-term memory), WAIS-R picture completion (visual organization and reasoning), WAIS-R digit symbol (performance measure with several components), WAIS-R block design (construction), and category naming of animals (word fluency). Although there were significant intercorrelations between these measures ${ }^{27}$ the predictive accuracy of the discriminant function incorporating all six measures was high. These data support the clinical use of an approach that combines a screening instrument like the mMMS with a neuropsychological test battery for predictive accuracy. Recent follow-up studies of subjects with ageassociated memory impairment ${ }^{41,42}$ and patients referred by family physicians ${ }^{43}$ also suggest that tests of recent memory and other neuropsychological measures show predictive utility for the final diagnosis of dementia on follow-up.

In a recent longitudinal study of normal older subjects in the community, four tests from the baseline neuropsychological test battery best predicted dementia after 4 years of follow-up: delayed recall on the SRT, the recall test from the Fuld Object Memory Evaluation, a verbal fluency test, and the WAIS digit symbol subtest. The model achieved an overall positive predictive value of $68 \%$, or three times the base rate, for prediction of the development of dementia. ${ }^{26}$ In a similar longitudinal community-based study from our center, baseline scores on the Boston Naming Test, immediate recall on the SRT, and the similarities subtest of the WAIS-R were significantly and independently associated with the later diagnosis of $\mathrm{AD} .{ }^{27}$ The profiles from these studies are similar to those observed in this QD study, despite the differences in the nature of samples (community, outpatient clinic).

Total mMMS scores were not predictive of the final diagnosis of dementia, or AD. Other studies indicate that total MMSE scores (Folstein) fail to detect subtle cognitive impairment in the very early stages of $\mathrm{AD}^{44}$ MMSE item structure has been compared cross-sectionally between patients and controls with specific neuropsychological test scores taken as arbitrary gold standards. ${ }^{45}$ In a study by the Consortium to Establish a Registry for Alzheimer's Disease 
(CERAD), delayed recall and the orientation items of day and date were the MMSE items that best distinguished AD from normal controls. ${ }^{46}$ In this QD sample, poor performance on the delayed recall item was predictive of the diagnosis of dementia, but disorientation was not predictive because of a ceiling effect, i.e., $91.6 \%$ of patients scored $\geq 8$ (maximum score 10). For the delayed recall item, the cutoff score of 1 (score of 0 or 1 versus 2 or 3 ) demonstrated the best predictive accuracy for the diagnosis of dementia. These data suggest that poor performance on the mMMS delayed recall item may be a useful predictor of the diagnosis of dementia (and AD) on follow-up.

Memory impairment is a cardinal feature of dementia. ${ }^{47}$ Several studies suggest that tests of delayed recall and longterm recall are more useful than tests of immediate recall in discriminating patients with very early dementia from normal control subjects in both clinical and community samples. ${ }^{10,26,31,48}$ However, delayed recall was not predictive of diagnostic outcome in the community sample from our center. $^{27}$ In this QD sample, delayed recall on the mMMS and consistent long-term retrieval on the SRT were predictive of diagnostic outcome. Although SRT total recall was not predictive, the results were in the expected direction and small sample size was a limitation.

The Washington University group reported that nearly all patients with a CDR of 0.5 met criteria for dementia at follow-up. ${ }^{12,14}$ This raises the following question: were the QD patients who eventually met criteria for dementia further along in their course of illness at baseline evaluation and, therefore, would the rest of the sample also have met criteria for dementia with longer follow-up? Some aspects of the data suggest otherwise. First, the final diagnosis of dementia was not associated with follow-up duration. Second, despite similar follow-up durations, the group that developed dementia showed a marked and significant drop in mMMS scores (and in other neuropsychological test scores, data not shown), but the rest of the sample showed no significant change. Finally, $51.7 \%$ of the baseline CDR $=.5$ group met criteria for dementia on follow-up, compared with $34.8 \%$ of the baseline CDR $=0$ group, a nonsignificant difference (Table 2 ). However, this difference was in the same direction as that reported by the Washington University group, and the relatively small sample of $Q D$ patients may have limited statistical power. Nonetheless, a CDR of 0.5 was not synonymous with very early dementia in this QD sample, suggesting that the prognosis for this group of patients may not be uniformly poor. The group identified as $\mathrm{CDR}=.5$ may vary considerably between settings, either because of patient or rater differences.

Increased age is a major risk factor for AD. ${ }^{12,49}$ Older QD patients were more likely to meet criteria for dementia (or AD) on follow-up. However, the inclusion of age as a variable in the discriminant function had only a marginal impact on predictive accuracy, and this may partly be related to this $\mathrm{QD}$ sample being younger than most $\mathrm{AD}$ samples. Educational attainment was not predictive of final diagnosis, but the paucity of patients with low educational status was a limitation. Subjective memory complaints were also not predictive of final diagnosis, and this has been observed previously in normal older people and in demented patients. ${ }^{50-52}$ Measures of depression and cerebrovascular disease were not predictive of diagnostic outcome. Among patients who met criteria for dementia on follow-up, the preponderance of $\mathrm{AD}$ was largely a function of the inclusion/exclusion criteria because several neurological disorders (including stroke) were excluded.

There were several limitations to this naturalistic longitudinal study. Although the results were not dissimilar to those reported in epidemiologic studies, ${ }^{23-27}$ it is unclear if these findings obtained in a specialty clinic are generalizable to community or primary care settings. ${ }^{43}$ The prospective standardized evaluation had to be supplemented by chart review to complete data acquisition. Statistical power was limited by sample size, and by the availability of baseline neuropsychological evaluation in only four-fifths of the sample. There was variation in duration of follow-up and considerable loss to follow-up $(40 \%)$. However, baseline demographics and indices of illness severity did not differ between those who did and did not return for follow-up. Additional methodological limitations were that the predictor variables, i.e., measures of cognitive impairment, were not evaluated systematically at annual intervals in all patients and were not truly independent of the outcome variable, i.e., the diagnosis of dementia, because by definition the type and severity of cognitive impairment is intrinsic to making the clinical diagnosis of dementia. ${ }^{53}$ These inherent limitations were addressed partly by the fact that despite similar follow-up durations, the group that eventually met criteria for dementia showed a marked and significant decrease in cognitive test performance, whereas the rest of the sample showed no significant change. This suggested different slopes for the changes in cognitive scores, but the lack of systematic neuropsychological testing at regular intervals during follow-up made it difficult to compare the slopes statistically. Of note, the results do not provide sufficient evidence for these neuropsychological measures to predict decline in any individual patient. Another limitation was the absence of pathological confirmation of the diagnosis of $\mathrm{AD}$ (and other dementias), primarily because there were few deaths during follow-up in this QD sample.

Several biological markers have shown predictive utility in distinguishing $\mathrm{AD}$ patients from normal control subjects. These putative biological markers include olfactory dysfunction, ${ }^{54,55}$ peripheral indices of cholinergic activity, ${ }^{56,57}$ pupillary dilatation in response to a cholinergic antagonist, ${ }^{58}$ the presence of the ALZ-50 protein in cerebrospinal fluid, ${ }^{59}$ parietotemporal blood flow deficit on SPECT and PET, $60-62$ hippocampal and medial temporal atrophy on $\mathrm{CT}^{63}$ and MRI $^{64,65}$ scan of brain, elevation of CSF microtubuleassociated tau protein, ${ }^{66,67}$ and reduction of $\beta$-Amyloid Peptide $_{42}$ in CSF. ${ }^{68}$ The association between the presence of the apolipoprotein- $\epsilon 4$ allele and $\mathrm{AD}$ is now well-established, ${ }^{15,16}$ but there is conflicting evidence regarding its predictive utility in cognitively impaired outpatients ${ }^{69,70}$ and in community samples. ${ }^{71}$ For an early diagnostic marker, it is more important to establish predictive utility in QD than to distinguish established cases of probable AD from normal control subjects. Predictive utility in QD remains to be firmly established for any of these putative biological markers. Currently, as demonstrated in this study, cognitive test performance remains critical to establish the diagnosis of dementia and to predict outcome. Other factors, including some that may not yet be identified, will likely prove important in prediction of outcome.

In this QD sample, there was considerable heterogeneity in outcome. At follow-up, a large proportion were rated as 
not demented $(44 \%)$ and an equally large proportion met criteria for dementia $(41.3 \%)$, with only a small number $(\mathbf{1 4 . 7 \% )}$ remaining in the "uncertain" dementia category. This heterogeneity in diagnostic outcome, with the largest groups in the "dementia" and "no dementia" categories, enhances the feasibility of further development of potential predictors of outcome in prospective, longitudinal studies of patients with QD.

\section{REFERENCES}

1. Philpot MP, Levy R. A memory clinic for the early diagnosis of dementia. Int J Geriatr Psychiatry 1987;2:195-200.

2. O'Neill D, Surmon GK, Wilcock GK. Longitudinal diagnosis of memory disorders. Age and Aging 1992;21:393-397.

3. Reinikainen KJ, Koivisto K, Mykkanen l. Age-associated memory impairment in aged population: An epidemiological study. Neurology 1990;40:177.

4. Coria F, Gomez de Caso JA, Minguez L et al. Prevalence of age-associated memory impairment and dementia in a rural community. J Neurol Neurosurg Psychiatry 1993;56:973-976.

5. Berg L. Does Alzheimer's disease represent an exaggeration of normal aging? Arch Neurol 1985;42:737-739.

6. Barker A, Jones R. Age-associated memory impairment: Diagnostic and treatment issues. Int J Geriatric Psychiatry 1993;8:305-310.

7. Kral VA. Senescent forgetfulness, benign and malignant. Can Med Assoc J 1962;86:2.57-260.

8. Reisberg B, Ferris SH, Franssen E et al. Age-associated memory impairment: The clinical syndrome. Dev Neuropsychology 1986;2:401-412.

9. Youngiohn JR, Crook III TH. Stability of everyday memory in ageassociated memory impairment: a longitudinal study. Neuropsychology 1993;7:406-416.

10. Flicker C, Ferris SH, Reisberg B. Mild cognitive impairment in the elderly: Predictors of dementia. Neurology 1991;41:1006-1009.

11. O'Brien JT, Beats B, Hill K et al. Do subjective memory complaints precede dementia? A three-year follow-up of patients with supposed 'benign senescent forgetfulness'. Intl J Geriatric Psychiatry 1992;7:481-486.

12. Rubin EH, Storandes M, Miller JP et al. Influence of age on clinical and psychometric assessment of subjects with very mild or mild dementia of the Alzheimer type. Arch Neurol 1993;50:380-383.

13. Hughes CP, Berg L, Danzinger WL et al. A new clinical scale for the staging of dementia. Br J Psychiatry 1982;140:566-572.

14. Storandt M, Hill RD. Very mild senile dementia of the Alzheimer type. Arch Neurol 1989;46:383-386

15. Saunders AM, Strittmatter WJ, Schmechel D et al. Association of apolipoprotein $\mathrm{E}$ allele $\epsilon 4$ with late-onset Alzheimer's disease. Neurology 1993;43:1467-1472.

16. Mayeux R, Stern Y, Ottman R et al. The apolipoprotein 64 allele in patients with Alzheimer's disease. Ann Neurol 1993;34:752-754.

17. Mayeux R, Sano M, Chen J et al. Risk of dementia in first-degree relatives of patients with Alzheimer's disease and related disorders. Arch Neurol 1991;48:269-273.

18. Chandra V, Kokmen E, Schoenberg BS, Beard CM. Head trauma with loss of consciousness as a risk factor for Alzheimer's disease. Neurology 1989;39:1576-1578.

19. Jorm AF, Van Duijn CM, Chandra V et al. Psychiatric history and related exposures as risk factors for Alzheimer's disease: A collaborative re-analysis of case-control studies. Int J Epidemiology 1991;20:\$43-\$47.

20. Amaducci I.A, Fratiglioni L, Rocca WA et al. Risk factors for clinically diagnosed Alzheimer's discase: A case-control study of an Italian population. Neurology 1986;36:922-9.31.

21. Shalat SL, Seltzer B, Pidcock C, Baker EL. Risk factors for Alzheimer's disease: A case-control study. Neurology 1987;37:1630-1633.

22. Stern Y, Gurland B, Tatemichi TK et al. Influence of education and occupation on the incidence of Alzheimer's discase. JAMA 1994;271:1004-1010.

23. Persson G, Skoog 1. Subclinical dementia: Relevance of cognitive symptoms and signs. J Geriatr Psychiatry Neurol 1992;5:172-178.

24. Fuld PA, Masur DM, Blau AD et al. Object-memory evaluation for prospective detection of dementia in normal functioning elderly: Predictive and normative data. J Clin Exper Neuropsychol 1990;12:520-528.

25. Fuld PA, Dickson D, Crystal H, Aronson MK. Primitive plaques and memory dysfunction in normal and impaired clderly persons. N Engl J Med 1987;316:756.

26. Masur DM, Sliwinski M, Lipton RB et al. Neuropsychological prediction of dementia and the absence of dementia in healthy elderly persons. Neurology 1994;44:1427-1432.
27. Jacobs DM, Sano M, Dooneief G et al. Neuropsychological detection and characterization of preclinical Alzheimer's disease. Neurology 1995;45:957962.

28. Knopman DS, Ryeberg S. A verbal memory test with high predictive accuracy for dementia of the Alzheimer type. Arch Neurol 1989;46:141-145.

29. Bayles $\mathrm{K}$, Boone $\mathrm{D}$, Tomoeda $\mathrm{C}$ et al. Differentiating Alzheimer's patients from the normal elderly and stroke patients with aphasia. J Speech Hear Disord 1989;54:74-87.

30. Becker JT, Huff J, Nebes RD et al. Neuropsychological function in Alzheimer's disease. Arch Neurol 1988;45:263-268.

31. Robinson-Whelen $S$, Storandt $M$. Immediate and delayed prose recall among normal and demented adults. Arch Neurol 1992;49:32-34.

32. American Psychiatric Association Diagnostic and Statistical Manual of Mental Disorders, 3rd Ed. revised Washington, DC: American Psychiatric Press, Inc., 1987.

33. Lesser RP, Fahn S, Snider SR et al. Analysis for the clinical problems in parkinsonism and the complications of long-term levodopa therapy. Neurology 1979;29:1253-1260.

34. Rosen WG, Terry RD, Fuld PA ct al. Pathological verification of ischemia score in differentiation of dementias. Ann'Neurol 1980;7:486-488.

35. Blessed G, Tomlinson BE, Roth $M$. The association between quantitative measures of dementia and of senile change in the cerebral grey matter of elderly subjects. Br J Psychiatry 1968;114:797-811.

36. Stern $Y$, Andrews H, Pittman J et al. Diagnosis of dementia in a heterogeneous population: Development of a neuropsychological paradigm-based diagnosis of dementia and quantified correction for the effects of education. Arch Neurol 1992;49:453-460.

37. Folstein M, Folstein S, McHugh P. "Mini-mental state". A practical method of grading the cognitive state of patients for clinicians. J Psychiatr Res 1975;12:189-198.

38. Mayeux R, Stern Y, Rosen J, Leventhal J. Depression, intellectual impairment and Parkinson's disease. Neurology 1981;31:645-650.

39. Stern Y, Sano MP, Paulson J, Mayeux R. Modified mini-mental state examination: Validity and reliability. Neurology 1987;37(Suppl 1):179.

40. McKhann G, Drachman D, Folstein M. Clinical diagnosis of Alzheimer's disease: Report of the NINCDS-ADRDA Work Group under the auspices of Department of Health and Human Services Task Force on Alzheimer's disease. Neurology 1984;34:939-944.

41. Small GW, LaRue A, Komo $S$ et al. Predictors of cognitive change in middleaged and older adults with memory loss. Am J Psychiatry 1995;152:17571764.

42. Hänninen $T$, Hallikainen $M$, Koivisto $K$ et al. A follow-up study of ageassociated memory impairment: Neuropsychological predictors of dementia. J Am Geriatr Soc 1995;43:1007-1015.

43. Tierney MC, Szalai JP, Snow WG et al. Prediction of probable Alzheimer's disease in memory-impaired patients: A prospective longitudinal study. Neurology $1996 ; 46: 661-665$.

44. Galasko D, Corey-Bloom J, Thal LY. Monitoring progression in Alzheimer's disease. J Am Geriatr Soc 1991;39:932-941.

45. Feher EP, Mahurin RK, Doody RS et al. Establishing the limits of the minimental state. Arch Neurol 1992;49:87-92.

46. Fillenbaum GG, Wilkinson WE, Welsh KA, Mohs RC. Discrimination between stages of Alzheimer's disease with subsets of mini-mental state examination items. Arch Neurol 1994;51:916-921.

47. Corey-Bloom J, Thal LJ, Galasko D et al. Diagnosis and evaluation of dementia. Neurology 1995;45:211-218.

48. Welsh K, Butters N, Hughes J et al. Detection of abnormal memory decline in mild cases of Alzheimer's Disease using CERAD neuropsychological measures. Arch Neurol 1991;48:278-281.

49. Evans DA, Funkenstein H, Albert MS et al. Prevalence of Alzheimer's disease in a community population of older persons. JAMA 1989;262:25512556.

50. Bolla KI, Lindgren KN, Bonaccorsey C, Bleeker ML. Memory complaints in older adults: Fact or fiction? Arch Neurol 1991;48:61-66.

51. La Rue A, Watson J, Plotkin DA. First symptoms of dementia: A study of relatives' reports. Intl J Geriatr Psychiatry 1993;8:239-245.

52. Feher EP, Larrabee GJ, Sudilovsky A, Crook III TH. Memory self-report in Alzheimer's disease and in age-associated memory impairment. J Geriatr Psychiatry Neurol 1994;7:58-65.

53. Wasson JH, Sox HC, Neff RK, Goldman L. Clinical prediction rules: Applications and methodological standards. N Engl J Med 1985;313:793-9.

54. Koss E. Olfactory dysfunction in Alzheimer's disease. Develop Neuropsychol 1986;2:89.

S5. Rai GS, Wright G. Tests for differential diagnosis of dementia of the Alzheimer's type. J Am Geriatr Soc 1988;36:285.

56. Kessler JA. Deficiency of a cholinergic differentiating factor in fibroblasts of patients with Alzheimer's disease. Ann Neurol 1987;21:95-98. 
57. Hartikainen P, Reininkainen KJ, Soininen $\mathrm{H}$ et al. Neurochemical markers in the cerebrospinal fluid of patients with Alzheimer's disease, Parkinson's disease and amyotrophic lateral sclerosis and normal controls. J Neural Transm Park Dis Dement Sect 1992;4:53-68.

58. Scinto LFM, Daffner KR, Dressler $D$ et al. A potential noninvasive neurobiological test for Alzheimer's disease. Science 1994;266:1051-1054.

59. Wolozin BL, Pruchnicki A, Dickson DW, Davies P. A neuronal antigen in the brains of Alzheimer patients. Science 1986;232:648-650.

60. Parnetti L, Lowenthal DT, Presciutti O et al. ${ }^{1} \mathrm{H}-\mathrm{MRS}, \mathrm{MRI}$ hippocampal volumetry, and ${ }^{99 m}$ TC-HMPAO-SPECT in normal aging, age-associated memory impairment, and probable Alzheimer's disease. J Am Geriatr Soc 1996;44:133-138.

61. Jagust WJ, Budinger TF, Reed BR. The diagnosis of dementia with single photon emission computed tomography. Arch Neurol 1987;44:258-262.

62. Holman BL, Johnson KA, Gerada B, et al. The scintigraphic appearance of Alzheimer's disease: A prospective study using technetium-99 m-HMPAO SPECT. J Nucl Med 1992;33:181-185.

63. de Leon MJ, Golomb J, Convit A et al. Measurement of medial temporal lobe atrophy in diagnosis of Alzheimer's disease. Lancet 1993;341:12.5-126.

64. Pearlson GD, Harris GJ, Powers RE et al. Quantitative changes in mesial temporal volume, regional cerebral blood flow, and cognition in Alzheimer's disease. Arch Gen Psychiatry 1992;49:402-408.
65. Erkinjurti T, Lee DH, Gao F et al. Temporal lobe atrophy on magnetic resonance imaging in the diagnosis of early Alzheimer's disease. Arch Neurol 1993;50:305-310.

66. Tato RE, Frank A, Hernanz A. Tau protein concentrations in cerebrospinal fluid of patients with dementia of the Alzheimer type. J Neurol Neurosurg Psychiatry 1995;59:280-283.

67. Vigo-Pelfrey C, Seubert P, Barbour $R$ et al. Elevation of microtubuleassociated protein tau in the cerebrospinal fluid of patients with Alzheimer's disease. Neurology 1995;45:788-793.

68. Motter R, Vigo-Pelfrey C, Kholodenko D et al. Reduction of $\beta$-Amyloid peptide $_{42}$ in the cerebrospinal fluid of patients with Alzheimer's disease. Ann Neurol $1995 ; 38: 643-648$.

69. Peterson RC, Smith GE, Ivnik RJ et al. Apolipoprotein $\mathrm{E}$ status as a predictor of the development of Alzheimer's disease in memory-impaired individuals. JAMA 1995;273:1274-1278.

70. Tierney MC, Szalai JP, Snow WG et al. A prospective study of the clinical utility of ApoE genoype in the prediction of outcome in patients with memory impairment. Neurology 1996;46:149-154.

71. Myers RH, Schaefer EJ, Wilson PWF et al. Apolipoprotein E $€ 4$ association with dementia in a population in a population-based study: The Framingham study. Neurology 1996;46:673-677.

\section{Inclusion Criteria}

1. Age $>40$ years.

2. Intellectual impairment present for a minimum of 6 months and a maximum of 10 years.

3. Diagnosis of "not demented" or "questionably demented" based on diagnostic evaluation. Patients rated "not demented" were required to have at least minimal evidence of cognitive impairment on clinical or neuropsychological evaluation. Those judged to be totally normal were excluded (i.e., $\mathrm{CDR}=0, \mathrm{mMMS}=57$ out of 57 , and a normal age-adjusted performance on neuropsychological testing).

4. Clinical Dementia Rating (CDR) of 0 (no dementia) or 0.5 (questionable dementia), based on original Washington University criteria. ${ }^{13}$

5. Modified Mini Mental State score $>30$ (range 0-57).

6. Based on standard policy in the clinic, a family member or close friend served as patient advocate or informant.

\section{Exclusion Criteria}

1. Established diagnosis of dementia and CDR score of 1 or greater.

2. Current clinical evidence of schizophrenia, schizoaffective disorder or primary major affective disorder. Pa- tients with a prior history of major affective disorder were included.

3. Electroconvulsive therapy within the past 6 months.

4. Current or recent (past 6 months) alcohol or substance dependence, by DSM-III-R criteria. An earlier history of alcohol abuse or substance abuse was not grounds for exclusion.

5. Clinical or historical evidence of stroke. Patients with radiological evidence of "lacunes" or small "vascular" lesions present in deep, periventricular or subcortical areas on MRI scan were not excluded, provided these were clinically and historically silent. Infarcts greater than $2 \mathrm{~cm}$ diameter in any slice or a stroke clearly extending into the cortex (radiologist assessment), were grounds for exclusion.

6. Use of concomitant medication(s) deemed to be the likely etiology for cognitive impairment.

7. CNS infection, posttraumatic dementia, toxicmetabolic encephalopathy, Huntington's disease, multiple sclerosis, diagnosis of Parkinson's disease before the onset of intellectual decline, mental retardation, primary untreated endocrine diseases, e.g., Cushing's disease or primary hypothalamic failure (well-treated hypothyroidism was not excluded). 